Biologia Futura

https://akademiai.com/loi/019

\title{
Sertraline in combination with sorafenib: A promising pharmacotherapy to target both depressive disorders and hepatocellular cancer
}

\section{Original Article}

Cite this article: Ozunal ZG, Donmez Cakil $\mathrm{Y}$, Isan $\mathrm{H}$, Saglam E, and Aktas RG. 2019. Sertraline in combination with sorafenib: A promising pharmacotherapy to target both depressive disorders and hepatocellular cancer. Biol. Fut. 70, 341-348.

Received: 16 May 2019

Accepted: 5 November 2019

Keywords:

sertraline, sorafenib, pharmacotherapy

\section{Zeynep Gunes Ozunal ${ }^{1,2}$, Yaprak Donmez Cakil ${ }^{2,3}$, Hatice Isan ${ }^{2}$,} Esra Saglam ${ }^{1}$ and Ranan Gulhan $\mathrm{Aktas}^{2,3}$

\footnotetext{
${ }^{1}$ Department of Medical Pharmacology, Faculty of Medicine, Maltepe University, Istanbul, Turkey

${ }^{2}$ Cancer and Stem Cell Research Center (MUKKAM), Maltepe University, Istanbul, Turkey ${ }^{3}$ Department of Histology and Embryology, Faculty of Medicine, Maltepe University, Istanbul, Turkey
}

DOI: $10.1556 / 019.70 .2019 .39$

Introduction: Hepatocellular carcinoma (HCC) is found within the first five most common tumors worldwide. Sorafenib is an approved agent in HCC treatment. Sertraline is a selective serotonin reuptake inhibitor. The aim of the study is to investigate the combination of sertraline and sorafenib at hepatocellular cancer cell proliferation and death. Methods: HepG2 cells were treated with drugs and viability test XTT was performed. Cells were stained with hematoxylin and eosin for histological examination or with anti-Bcl-2 antibody and Hoechst 33258 for immunofluorescence. Results: Viability results supported dose-dependent antiproliferative effect for both sertraline and sorafenib. Microscopic evaluation of stained cells exerts morphological changes. Discussion: This is the first study to show that sorafenib and sertraline have synergistic effect in hepatocellular cancer. 
Besides its well-known clinical uses, effects of sertraline on cancer were also investigated. Sertraline was studied in several cell lines, such as hepatic cells, colon cancer cell lines, and hematological cancers for a potential anticancer activity (Chen et al., 2014b; Gil-Ad et al., 2008; Xia et al., 2017). Sorafenib was evaluated in hepatocellular cancer cell lines where it inhibited cell proliferation (Wei et al., 2015). Recently, drug combinations became a promising approach to obtain a better outcome at lower doses overcoming drug inefficacy. To the best of our knowledge, drug combination studies examining the effect of sertraline and sorafenib combination on hepatocellular cancer cell proliferation are lacking. The known requirement for new therapeutic approaches for $\mathrm{HCC}$ treatment prompted us to investigate the combination of sertraline and sorafenib at hepatocellular cancer cell proliferation and death.

\section{MATERIALS AND METHODS}

\section{Cell culture and drugs}

The human HCC cell line HepG2 (ATCC) was maintained in Dulbecco's modified Eagle's medium supplemented with L-glutamine, $10 \%(\mathrm{v} / \mathrm{v})$ heat-inactivated fetal bovine serum, and $100 \mathrm{IU} / \mathrm{ml}$ penicillin and $100 \mu \mathrm{g} / \mathrm{ml}$ streptomycin in a humidified atmosphere of $5 \% \mathrm{CO}_{2}$ at $37{ }^{\circ} \mathrm{C}$.

Sorafenib and sertraline (Sigma-Aldrich, St. Louis, MO, USA) were dissolved in DMSO and in water, respectively, at a concentration of $10 \mathrm{mmol} / \mathrm{L}$. Drugs were freshly diluted in culture medium before use. Control group refers to untreated cells.

\section{XTT cell viability assay}

HepG2 cells were seeded at a density of 10,000 cells per well in 96-well plates. In the following day, the cells were treated with drugs and incubated for $24 \mathrm{hr}$.

To evaluate the effects of the drugs alone and in combination on cell viability, three different sets of treatments were carried out: (a) sorafenib with a maximum concentration of $50 \mu \mathrm{M}$, (b) sertraline with a maximum concentration of $42.4 \mu \mathrm{M}$, and (c) combination of sorafenib and sertraline with the above-specified maximum concentrations. Both drugs were administered with a dilution ratio of $3 / 4$. After incubation, XTT reagent (Biological Instruments) was added according to manufacturer's instructions, and the optical density of the soluble product was measured at $500 \mathrm{~nm}$ with a Synergy Microplate Reader.

$\mathrm{IC}_{50}$ values of sertraline and sorafenib, the drug concentrations resulting in $50 \%$ inhibition of cell proliferation, were calculated by non-linear regression analysis on MS Excel software. Bar graphs were generated using GraphPad Prism V.8.01 (San Diego, CA, USA).

The effects of drug combinations were evaluated using "Synergy finder" (https://synergyfinder.fimm.fi), a webbased application developed to analyze the dose-response matrix data (Ianevski et al., 2017). Synergy scores for doseresponse matrix data were calculated with Bliss model as the two drugs act independently (Bliss, 1939).

\section{Phase contrast microscopy}

HepG2 cells were seeded on cover slips in 24-well plates and treated with $\mathrm{IC}_{50} / 2$ doses of drugs. After treatment, the cells were fixed in $4 \%$ paraformaldehyde in phosphatebuffered salin (PBS) and hematoxylin and eosin (H\&E) staining was performed. Photographs were captured under a Zeiss Primovert microscope (Jena, Germany).

\section{Immunofluorescence (IF) microscopy}

Cells were treated with $\mathrm{IC}_{50} / 2$ doses of drugs for $24 \mathrm{hr}$. Fixed HepG2 cells were blocked with bovine serum albumin (Capricorn, Ebsdorfergrund, Germany) and incubated with anti-human Bcl-2 antibody (1:100 dilution, Biocare med) overnight at $4{ }^{\circ} \mathrm{C}$. Next day, the cells were rinsed with PBS three times and incubated with goat anti-mouse IgG DyLight 488 (1:200, Thermo Scientific, Waltham, MA, USA) for 90 min at $37{ }^{\circ} \mathrm{C}$. After rinsing three times with PBS, the cells were counterstained with Hoechst 33258 (Thermo Scientific) for labeling the nuclei. Images were taken with a laser scanning confocal microscope (LSM 700, Zeiss).

\section{Flow cytometry}

Cell death was evaluated using Annexin V/propidium iodide (PI) apoptosis detection assay according to the manufacturer's instructions (BD Pharmingen, BD Biosciences, San Jose, CA, USA). Briefly, HepG2 cells were seeded into 6 -well plates and incubated overnight. Next day, they were treated with drugs and incubated for another $24 \mathrm{hr}$. $\mathrm{IC}_{50} / 2$ was the selected dose for sertraline, sorafenib, and combination treatments. After trypsinization, cells were suspended in $1 \times$ binding buffer [0.01 M Hepes/ $\mathrm{NaOH}(\mathrm{pH} 7.4), 0.14 \mathrm{M} \mathrm{NaCl}$, $2.5 \mathrm{mM} \mathrm{CaCl}_{2}$ ] at a concentration of $1 \times 10^{6}$ cells $/ \mathrm{ml}$. Cell suspension $(100 \mu \mathrm{l})$ was mixed with specified amounts of Annexin V-APC and PI. Flow cytometric analyses were carried out in a BD AccuriC6 Plus flow cytometer (BD Biosciences). A total of 20,000 events were collected for each sample. Percentages of viable cells (Annexin V-/PI-), early apoptotic cells (Annexin V+/PI-), and late apoptotic/ dead cells (Annexin V+/PI+) were examined. The percentage of apoptotic cells was calculated by summation of percentages of early apoptotic cells and late apoptotic/dead cells.

\section{Data analyses}

All data are expressed as mean \pm standard error of the mean. Statistical evaluation was performed by one-way analysis of variance (ANOVA) test using GraphPad Prism V.8.01 and post-hoc Tukey's analyses were carried out to find groups whose mean differences were significant. Data were pooled from at least three independent experiments.

\section{RESULTS}

Effects of sertraline and sorafenib alone or in combination on cell viability

To investigate the toxicity of sertraline and sorafenib alone or in combination in HepG2 cells and to determine the $\mathrm{IC}_{50}$ 
of respective drugs, XTT cell viability assay was performed. Sertraline inhibited HepG2 cell proliferation in a dosedependent manner after $24 \mathrm{hr}$ of treatment (Fig. 1a). Cells were exposed to increasing concentrations of sertraline with a maximum dose of $42.4 \mu \mathrm{M}$. $\mathrm{IC}_{50}$ value was found to be $9.6 \pm 2.2 \mu \mathrm{M}$ for sertraline. Similarly, antiproliferative effect of sorafenib was demonstrated in a dose-dependent manner after $24 \mathrm{hr}$ of treatment (Fig. 1b). $\mathrm{IC}_{50}$ was determined as $17.8 \pm 1.6 \mu \mathrm{M}$ for sorafenib.

Sertraline and sorafenib combination effect was visualized on a synergy landscape map over the dose matrix. Average Bliss synergy score was found to be -0.115 . The most synergistic area covers a dose range of 11.9-21.1 $\mu \mathrm{M}$ for sorafenib and $0-7.5 \mu \mathrm{M}$ for sertraline. An amount of $5.6 \mu \mathrm{M}$ of sertraline and $15.8 \mu \mathrm{M}$ of sorafenib were shown to be the doses exhibing highest synergy (d-score: 4,316; Fig. 1c and d showing 2D and 3D synergy maps, respectively). Positive d-score means a synergistic activity. Inhibition of cell proliferation in response to combination treatments can be examined on a dose-response matrix. Accordingly, while $17.8 \mu \mathrm{M}$ is the required sorafenib dose for a $50 \%$ reduction in cell proliferation, $6.7 \mu \mathrm{M}$ induces the same effect when in combination with $10 \mu \mathrm{M}$ sertraline.

\section{Histological examination of HepG2 cells after treatment with sertraline and sorafenib alone or in combination}

Effects of sertraline and sorafenib alone or in combination on cell morphology were examined by $H \& E$ staining. Phase contrast microscopic evaluations of H\&E-stained sections demonstrate typical morphological features of HepG2 cells for the control group (Fig. 2a and b). The adherent, epithelial-like cells grew in pile-up structures and were observed as small aggregates. Sertraline treatment with half of the $\mathrm{IC}_{50}$ dose $(4.8 \mu \mathrm{M})$ led to reduced cell density (Fig. 2c and d) visible in H\&E staining. Cell aggregates are less frequently found when compared with control group. The morphology of the cells was changed as well. They were more rounded and cytoplasmic vacuole formation was observed. Intracellular vacuoles were present in most cells and were not stained with $H \& E$ (a)

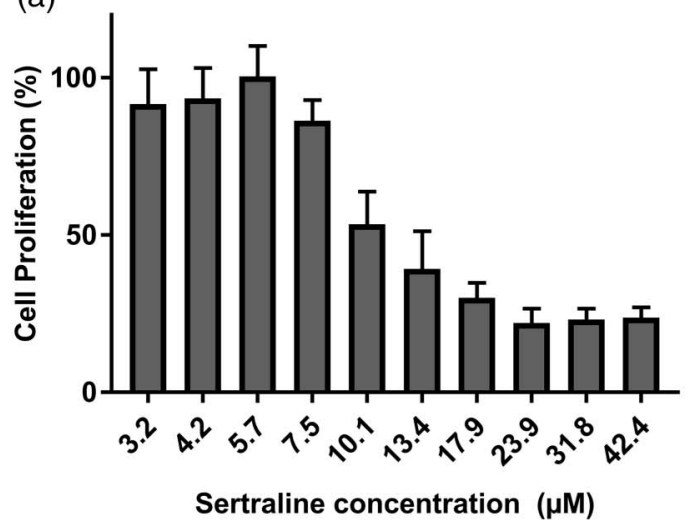

(c)

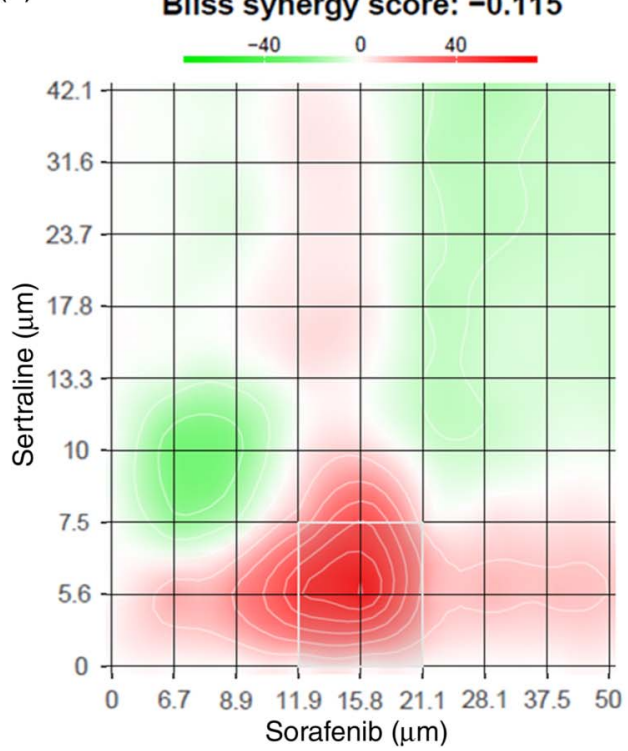

(b)

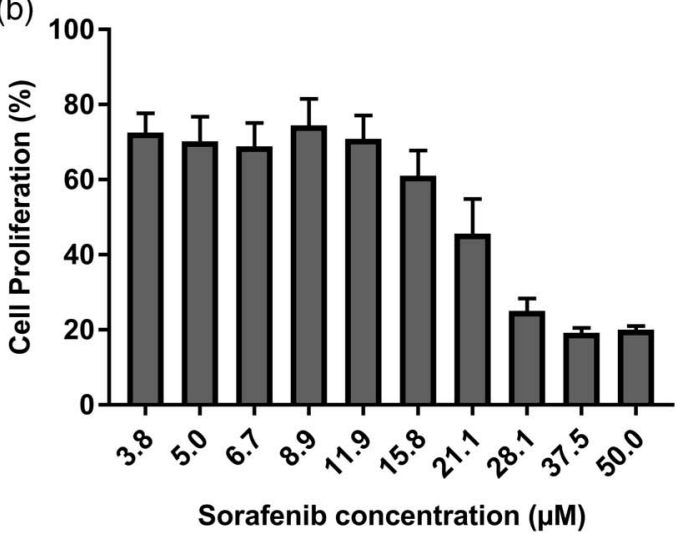

(d)
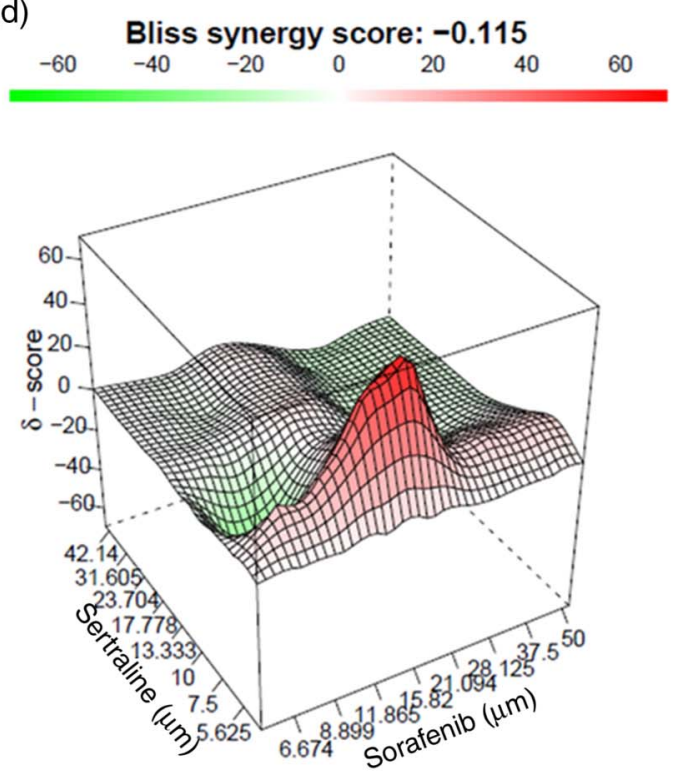

Fig. 1. HepG2 cells were exposed to increasing concentrations of (a) sertraline and (b) sorafenib for 24 hr. The graphs show a gradual decrease in cell proliferation with increasing drug concentrations. IC50 values were calculated by non-linear regression analysis. (c) 2D and (d) 3D synergy maps demonstrate the combination landscape of sertraline with sorafenib. The area colored darkest corresponds to the most synergistic area. 2D and 3D synergy maps are generated by "SynergyFinder" 


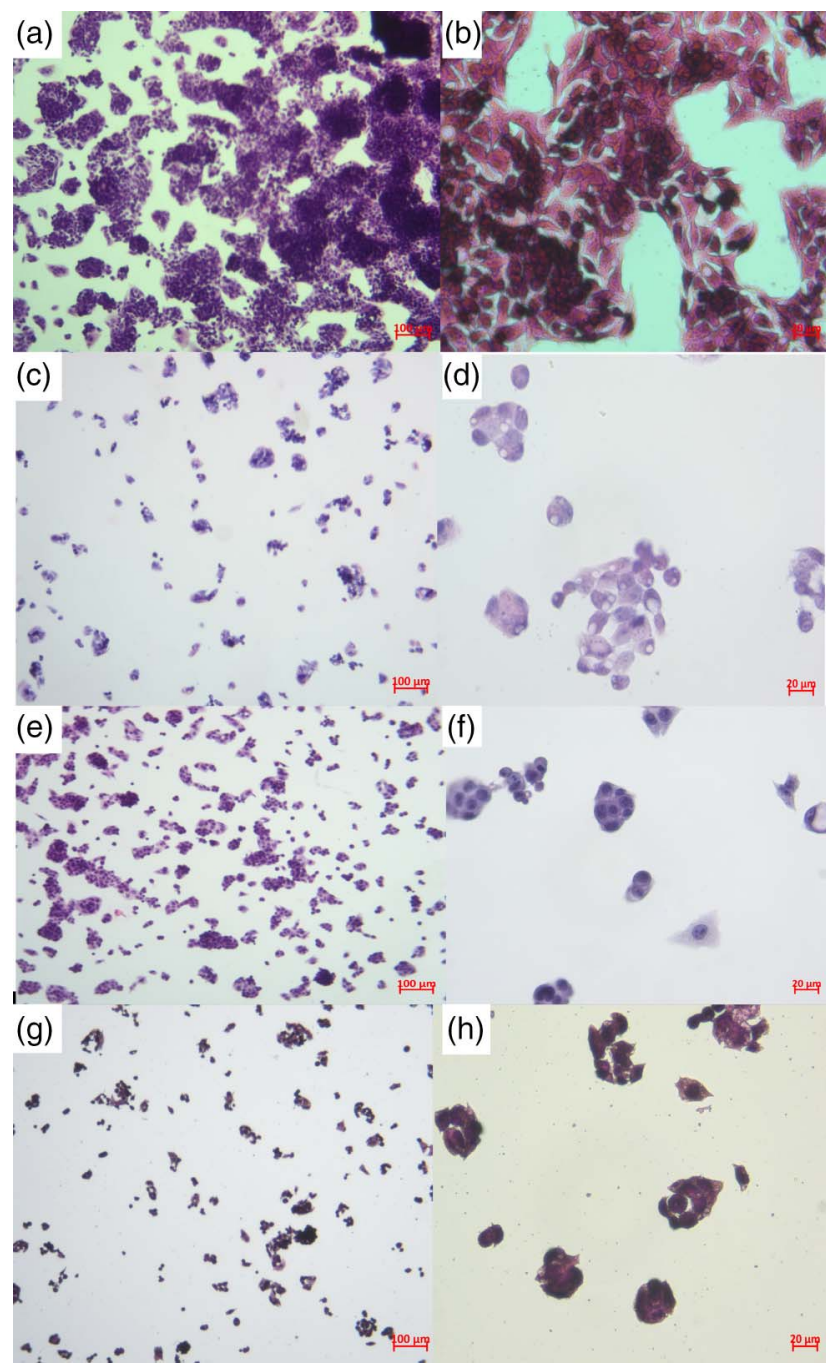

Fig. 2. HepG2 cells were stained with H\&E. (a) Control group without any treatment $10 \times$ magnification and

(b) $40 \times$ magnification, (c) sertraline $10 \times$ magnification and

(d) $40 \times$ magnification, (e) sorafenib $10 \times$ magnification, and (f) 40× magnification, (g) sertraline and sorafenib in combination $10 \times$ magnification, and (h) $40 \times$ magnification. Cells were treated with IC50/2 doses of drugs

(Fig. 2c and d). Round cell shape was observed in sorafenib-treated $(8.9 \mu \mathrm{M})$ group (Fig. 2e and f).

In addition to reduced cell density and changed morphology, combination therapy of sertraline and sorafenib also resulted in appearance of extremely dark stained cells, which is a sign of seriously destructed cells (Fig. $2 g$ and $h$ ). The results are concordant with cell viability assay with respect to the reduced cell density after treatments.

\section{IF analysis of HepG2 cells after treatment with drugs}

To evaluate the effects of sertraline and sorafenib alone or in combination on cellular morphology and apoptosis, cells were stained with Hoechst 33258 and Bcl-2 antibody. Intact nuclei of control cells were detected with Hoechst 33258. $\mathrm{Bcl}-2$ expression was visualized in cytoplasm and nucleus with IF staining in untreated cells (Fig. 3a). Nuclei were intact when the cells were exposed to sertraline, sorafenib,
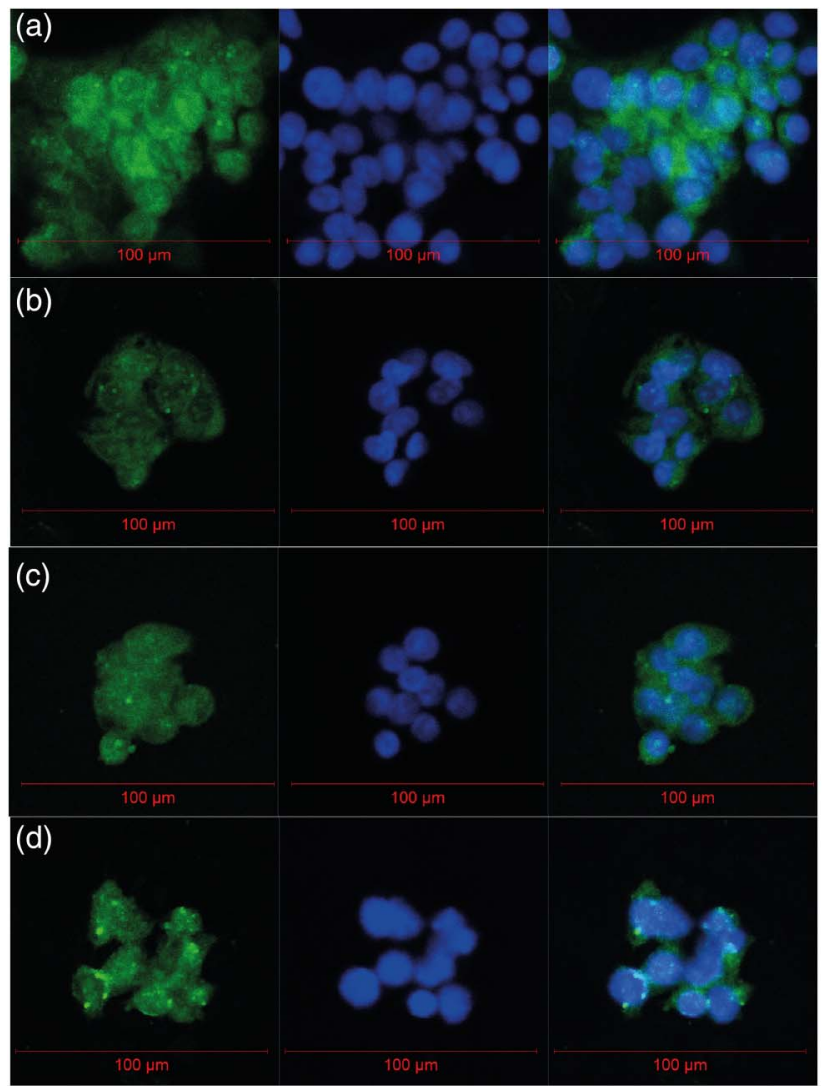

(f)

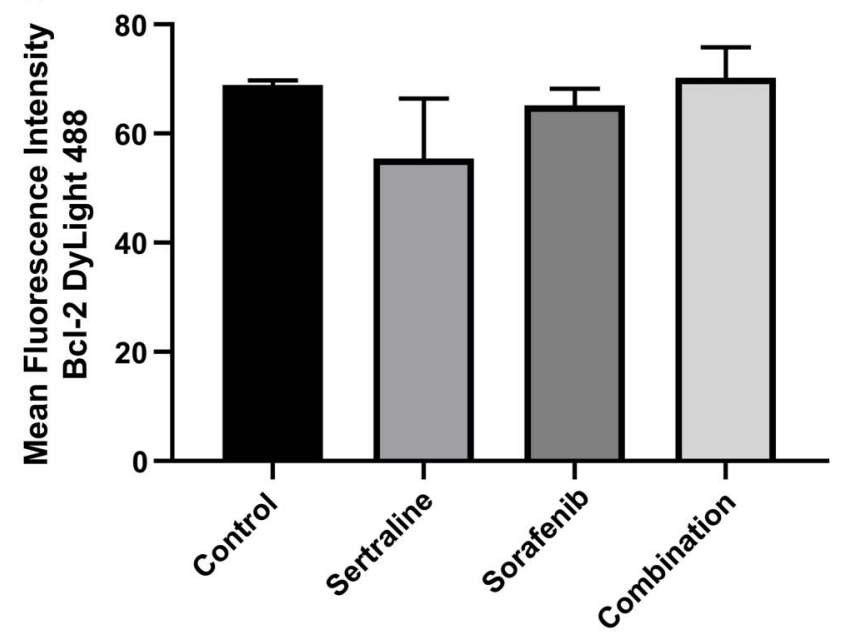

Fig. 3. HepG2 cells were exposed to IC50/2 doses of (a) control group without any treatment, (b) sertraline, (c)sorafenib, and

(d) sertraline and sorafenib in combination. After $24 \mathrm{hr}$ of incubation, they were labeled with the Bcl-2 antibody. DyLight ${ }^{\circledR}$ 488 was used as the secondary antibody. Hoechst 33258 staining was performed to visualize the nuclei. Images were merged right. (e) Mean fluorescence intensity of Bcl-2. There was no significant change between groups $F_{(3,8)}=1.102, p=.403$

or their combination and no chromatin condensation was observed (Fig. 3b-d). Cytoplasmic vacuoles were observed in sertraline-treated cells in correlation with phase contrast microscopic evaluations (Fig. 3b). The groups did not differ in fluorescence intensity of $\mathrm{Bcl}-2[F(3,8)=1.102, p=.403$; Fig. 3e]. The post-hoc analysis did not demonstrate significant difference between groups $(p>.05)$. 
(a)

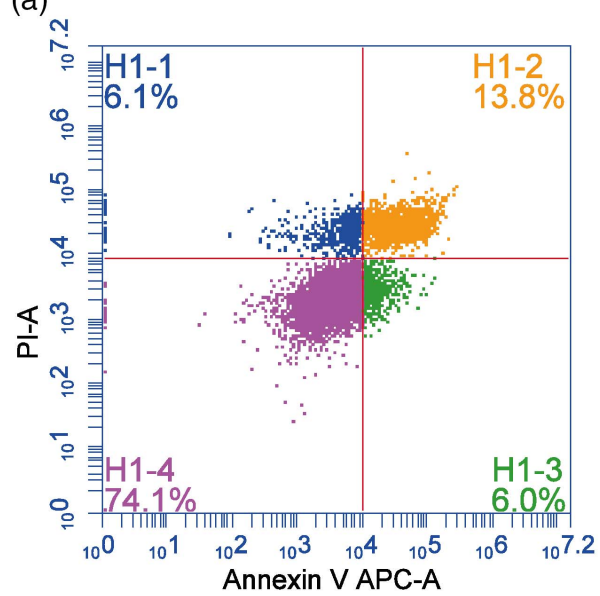

(c)

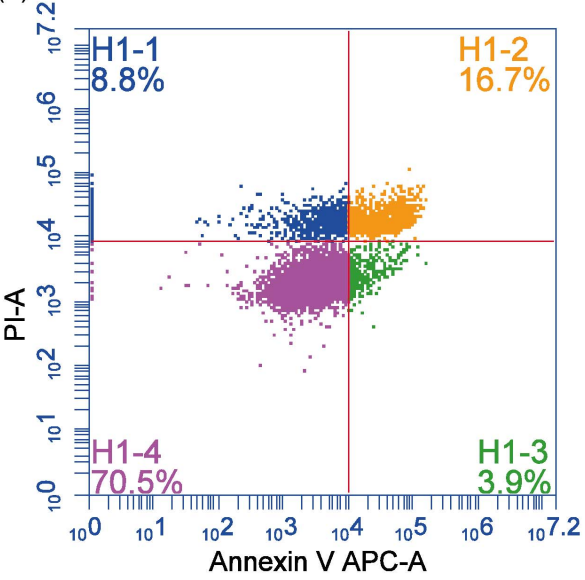

(b)

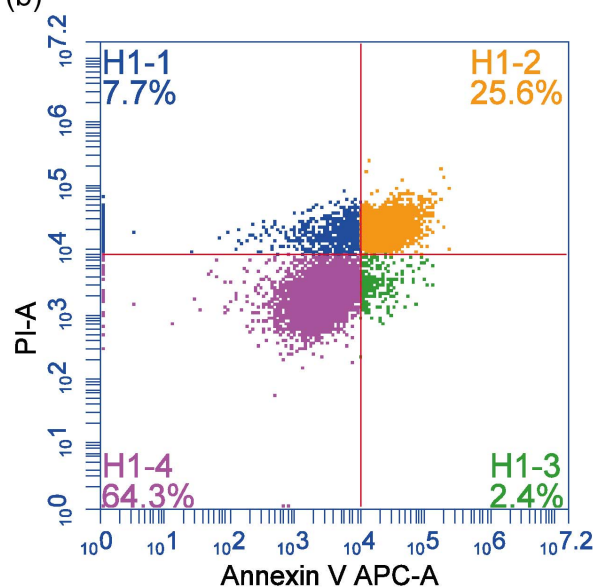

(d)

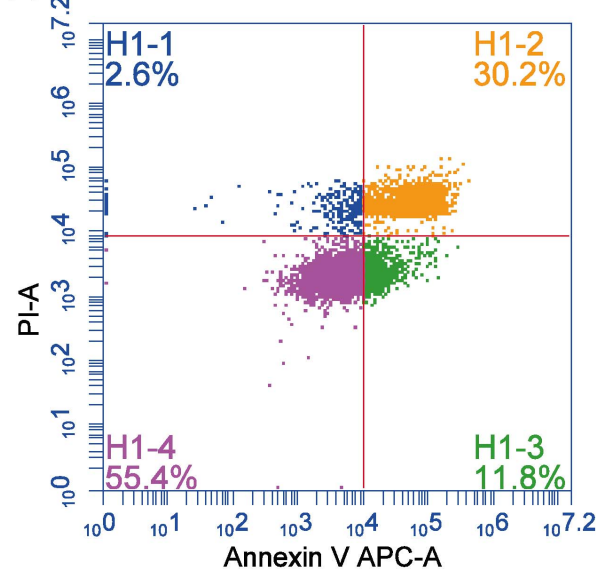

(e)

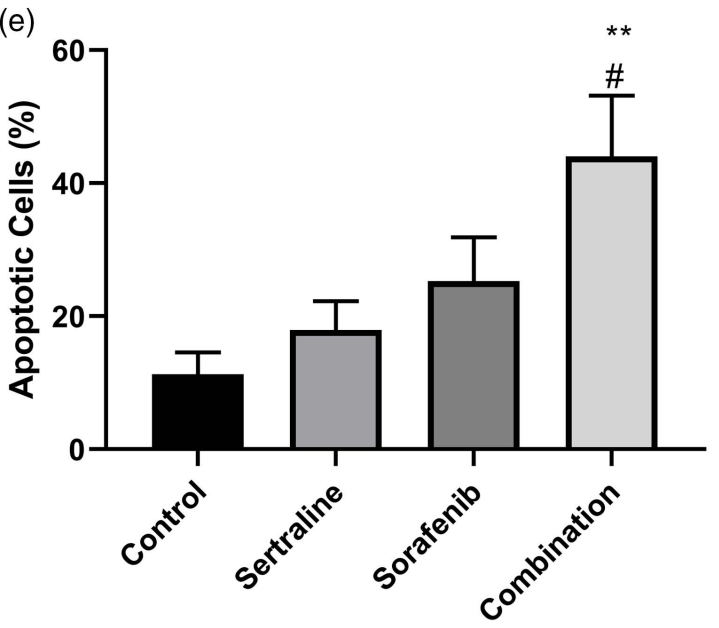

Fig. 4. HepG2 cells were stained with Annexin V/propidium iodide (PI) apoptosis detection assay. Dot plots represent (a) control group without any treatment, (b) sertraline, (c) sorafenib, (d) sertraline and sorafenib in combination. (e) Apoptotic cells (\%) were calculated by summation of percentages of early apoptotic cells (Annexin V+/PI-) and late apoptotic/dead cells (Annexin V+/PI+). The one-way ANOVA result showed significant difference among groups $F_{(3,24)}=5.079, p=.007$ Tukey's post-hoc test was carried out. **Significant difference between combination and control groups with $p<.01$. " Significant difference between combination and sertraline groups with $p<.05$

Flow cytometric analysis of HepG2 cells after treatment with sertraline and sorafenib alone or in combination

To examine the induction of apoptosis by drugs, Annexin V/ PI apoptosis detection assay was performed. Control group cells displayed a high live cell ratio (76.36 \pm 3.57 ; Fig. 4a). After treatment with sertraline and sorafenib, live cell ratio was found to be $69.73 \pm 7.99$ and $60.57 \pm 8.08$, respectively (Fig. 4b and c). The live cell ratio was $47.39 \pm 7.92$ after exposure of the cells to combination of both drugs. The oneway ANOVA test for the live cell ratio indicated a significant difference among groups $\left[F_{(3,24)}=3.079, p=.047\right]$. The post-hoc analysis demonstrated that the live cell ratio was significantly lower in combination group (Fig. 4d) when 
compared to control group $(p=.040)$. Other groups did not show a significant change in comparison to the control group.

Apoptotic cell percentage changed among the groups $\left[F_{(3,24)}=5.079, p=.007\right.$; Fig. 4e]. The post-hoc analysis revealed that sertraline and sorafenib in combination dramatically induced apoptosis. Apoptotic cell percentage increased in combination group $(44.01 \pm 9.18)$ when compared to control group $(11.26 \pm 3.33 ; p=.006)$ and sertraline-treated group $(17.93 \pm 4.35 ; p=.034)$. There was no difference between sorafenib-treated group $(25.29 \pm 6.57)$ and other groups for apoptotic cell percentage $(p>.05)$.

\section{DISCUSSION}

HCC is within the fastest growing causes of death in the world and has a significant economic impact (Ghouri et al., 2017). Sorafenib is the first approved pharmacological agent but prolongs survival for only few months (Daher et al., 2017). Certainly, better pharmacotherapy strategies are needed for hepatocellular cancer. Drug development is unfortunately long and expensive process. Drug repositioning, new uses for existing drugs, shortens the devolopment duration with reduced pharmacokinetic and safety uncertainty (Ashburn \& Thor, 2004). Psychiatric drugs are candidates for use in treatment of various cancers (Huang et al., 2018).

In this study, $\mathrm{IC}_{50}$ for sorafenib was found to be $17.8 \mu \mathrm{M}$. This result is comparible with the studies in literature. Cervello et al. (2012) reported $\mathrm{IC}_{50}$ of sorafenib as $19.5 \mu \mathrm{M}$ in HepG2 cell line and $15.5 \mu \mathrm{M}$ in Huh7 cell. Our results are in correlation with these findings. Sertraline, sorafenib, and their combination inhibited the proliferation of HepG2 cells in a dose-dependent manner (Fig. 1a-d). Moreover, single drugs or coadministration of sertraline and sorafenib induced apoptosis of HepG2 cells as shown by Annexin V/PI and H\&E stainings (Figs 2 and 4). Expression of the antiapoptotic protein Bcl-2 was visualized in cytoplasm and nucleus with IF staining. This is supported by previous experience (Hoetelmans et al., 2000).

This study first presents the morphological and apoptotic changes of HepG2 cells after treatment with the combination of sertraline and sorafenib. The sorafenib dose to inhibit proliferation is lower when used in combination than sorafenib used alone. Clinical important adverse reactions of sorafenib include skin toxicity, diarrhea, and hypertension. When the adverse drug reactions are severe, dose reduction is within the recommendations (Bellmunt et al., 2011). Combination with sertraline may lead to better safety profile. Evidences showed that sertraline could enhance the sensitivity of cells to several chemotherapy drugs, such as Ara-C, doxorubicin, and imatinib (Xia et al., 2017). Setraline and sorafenib exert apoptotic activity in combination.

Serotonin is reported to induce proproliferative effect in Huh7 cells but not in HepG2 and Hep3B cells and 5-HT2BR-FOXO3a pathway is indicated to be important in this effect (Liang et al., 2013). Serotonin transporters, the main target for sertraline, are not known to be present in HepG2 cell line and hepatocellular cancer (Kuwahara et al., 2015). Thus, the antiproliferative effect of sertraline in this study may not be expected to be related with the transporter. Morever, SSRIs are shown to activate $5-\mathrm{HT}_{2 \mathrm{~B}}$ receptors with an enhancement of protein kinase $\mathrm{C}$ activity and accumulation of intracellular $\mathrm{Ca}^{2+}$ (Peng et al., 2014). 5-HT receptor subtypes HTR1A, HTR1B, HTR2B, and HTR7 were found to be expressed in HCC patients and cell lines. Proliferation of $\mathrm{HCC}$ is correlated with increased expression of HTR1B and HTR2B (Soll et al., 2012).

SSRI is a widely used serotonin-related drug group and is also investigated in cancer treatment. A clinical correlation between SSRI use and decreased risk of HCC has been reported (Chan et al., 2018). It was shown that sertraline induced apoptosis with activation of JNK, but not ERK1/2 or p38 in the mitogen-activated protein kinase pathway (Chen et al., 2014b). Apoptosis was shown to be coupled to endoplasmic reticulum (ER) stress; MAP4K4-JNK signaling pathway contributed to the process of sertralineinduced ER stress (Chen et al., 2014a). Kuwahara et al. (2015) evaluated the effects of SSRIs including sertraline on HepG2 cells and concluded that the antitumor effect of SSRIs is dependent on activation of the caspase pathway and is unrelated to serotonin reuptake inhibition. Sertraline is also reported to downregulate AKT in melanoma cells (Reddy et al., 2008). Sertraline may exert antiproliferative effect in HepG2 cells, which is not mediated by serotonin transporter or receptor. In this study, we observed that sertraline leads to apoptotic and or non-apoptotic cell death that needs to be investigated in the future.

Sertraline has also sigma 1 agonist activity (Fishback et al., 2010). Sigma receptors are also defined as ER stress "gatekeepers." Agonism, which is a new target for cancer, is reported to induce ER stress (Tesei et al., 2018). Chen et al. (2014a) showed that ER stress markers have been changed in response to $3.13 \mu \mathrm{M}$ of sertraline in vitro. The mentioned dose corralates with the lowest dose in this study and is lower than $\mathrm{IC}_{50}(9.6 \mu \mathrm{M})$. The effect of sertraline on HepG2 cells may be related to ER stress. ER stress effect of sertraline needs to be evaluated to further enlighten the pathway.

Sertraline is reported to inhibit proliferation in renal cells by interacting with dopamine transporter (Schrödter et al., 2016). In HepG2 cells, dopamine receptor subtypes $\left(\mathrm{DRD}_{1}-\mathrm{DRD}_{5}\right)$ were shown to be expressed $(\mathrm{Xu}$ et al., 2014). The antiproliferative effect of sertraline on HepG2 cells may be mediated by dopamine.

This study first showed that sorafenib and sertraline have synergistic effect in hepatocellular cancer. The synergistic effect resulted in a lower sorafenib dose required when used in combination with sertraline. Dose reduction is very important clinical concern that decreases the rate of sorafenibrelated adverse drug reactions. Sertraline and sorafenib do not have known drug-drug interaction potential according to Lexicomp $^{\circledR}$ drug interactions software (Lexicomp, Wolters Kluwer Health, Inc., Riverwood, IL, USA) that can limit their use in combination (). Moreover, HCC is a risk factor for depressive disorders (Chang et al., 2015). Sertraline, an SSRI drug, is a recommended treatment for psychiatric disorders, which may also ameliorate HCC. Sorafenib in combination with sertraline is a promising pharmacotherapy to target both depressive disorders and HCC. Further studies are needed to evaluate the efficacy and safety of sertraline sorafenib combination therapy. 


\section{CONCLUSION FOR FUTURE BIOLOGY}

Drug repositioning is a promising strategy in drug development. Sertraline, an antidepressant drug, inhibited proliferation of hepatocellular cancer in vitro. Moreover, when administered with sorafenib, sertraline exerted synergistic activity to decrease the viability of HepG2 cells. Our research highlights the effects of sertraline and its combination with sorafenib on cell proliferation and death. It might promote further studies to enlighten the underlying mechanisms important for future biological research.

Acknowledgments: The authors would like to thank Ayça Karagöz for her assistance in IF staining.

\section{Ethical Statement: None.}

Funding Statement: This study was funded by Maltepe University Research Project Council (Grant date: March $28,2018)$.

Data Accessibility: This article contains all data analyzed during the study.

Competing Interests: The authors declare no competing interests.

Authors' Contributions: ZGO, YDC, and ES involved in study conception and design and drafting of the manuscript. ZGO, YDC, and HI involved in acquisition of data. ZGO, YDC, HI, and RGA involved in analysis and interpretation of data. ZGO, YDC, ES, and RGA involved in critical revision and spell corrections.

\section{REFERENCES}

Ashburn, T. T., Thor, K. B. (2004) Drug repositioning: identifying and developing new uses for existing drugs. Nat. Rev. Drug Discov. 3, 673-683.

Bellmunt, J., Eisen, T., Fishman, M., Quinn, D. (2011) Experience with sorafenib and adverse event management. Crit. Rev. Oncol. Hematol. 78, 24-32.

Bliss, C. I. (1939) The toxicity of poisons applied jointly. Ann. Appl. Biol. 26, 585-615.

Cervello, M., Bachvarov, D., Lampiasi, N., Cusimano, A., Azzolina, A., McCubrey, J.A., Montalto, G. (2012) Molecular mechanisms of sorafenib action in liver cancer cells. Cell Cycle 11, 2843-2855.

Chan, H. L., Chi, W. C., Chen, V. C., Huang, K. Y., Wang, T. N., Lee, Y., McIntyre, R. S., Hsu, T. C., Lee, C. T., Tzang, B. S. (2018) SSRIs associated with decreased risk of hepatocellular carcinoma: a population-based case-control study. Psychooncology 27, 187-192.

Chang, C. H., Chen, S. J., Liu, C. Y. (2015) Risk of developing depressive disorders following hepatocellular carcinoma: a nationwide population-based study. PLoS One 10, e0135417.

Chen, S., Xuan, J., Couch, L., Iyer, A., Wu, Y., Li, Q. Z., Guo, L. (2014a) Sertraline induces endoplasmic reticulum stress in hepatic cells. Toxicology 322, 78-88.
Chen, S., Xuan, J., Wan, L., Lin, H., Couch, L., Mei, N., Dobrovolsky, V. N., Guo, L. (2014b) Sertraline, an antidepressant, induces apoptosis in hepatic cells through the mitogenactivated protein kinase pathway. Toxicol. Sci. 137, 404-415.

Daher, S., Massarwa, M., Benson, A. A., Khoury, T. (2017) Current and future treatment of hepatocellular carcinoma: an updated comprehensive review. J Clin. Transl. Hepatol. 6, 69-78.

DeVane, C. L., Liston, H. L., Markowitz, J. S. (2002) Clinical pharmacokinetics of sertraline. Clin. Pharmacokinet. 41, 1247-1266.

Fishback, J. A., Robson, M. J., Xu, Y. T., Matsumoto, R. R. (2010) Sigma receptors: potential targets for a new class of antidepressant drug. Pharmacol. Ther. 127, 271-282.

Ghouri, Y. A., Mian, I., Rowe, J. H. (2017) Review of hepatocellular carcinoma: epidemiology, etiology, and carcinogenesis. $J$. Carcinog. 16, 1.

Gil-Ad, I., Zolokov, A., Lomnitski, L., Taler, M., Bar, M., Luria, D., Ram, E., Weizman, A. (2008) Evaluation of the potential anti-cancer activity of the antidepressant sertraline in human colon cancer cell lines and in colorectal cancer-xenografted mice. Int. J Oncol. 33, 277-286.

Hoetelmans, R., Van Slooten, H. J., Keijzer, R., Erkeland, S., van de Velde, C. J., Dierendonck, J. H. (2000) Bcl-2 and Bax proteins are present in interphase nuclei of mammalian cells. Cell Death Differ. 7, 384-392.

Ianevski, A., He, L., Aittokallio, T., Tang, J. (2017) SynergyFinder: a web application for analyzing drug combination doseresponse matrix data. Bioinformatics 33, 2413-2415.

Huang, J., Zhao, D., Liu, Z., Liu, F. (2018) Repurposing psychiatric drugs as anti-cancer agents. Cancer Lett. 419, 257-265.

Joong, S. S., Liu, J. O. (2014) Recent advances in drug repositioning for the discovery of new anticancer drugs. Int. J. Biol. Sci. 10, 654-663.

Keating, G. M., Santoro, A. (2009) Sorafenib: a review of its use in advanced hepatocellular carcinoma. Drugs 69, 223-240.

Kuwahara, J., Takaaki, Y., Nobuaki, E., Mitsuyo, U., Nina, Z., Soichiro, U., Satohiro, M. (2015) Comparison of the antitumor effects of selective serotonin reuptake inhibitors as well as serotonin and norepinephrine reuptake inhibitors in human hepatocellular carcinoma cells. Biol. Pharm. Bull. 38, 1410-1414.

Liang, C., Chen, W., Zhi, X., Ma, T., Xia, X., Liu, H., Zhang, Q., Hu, Q., Hang, Y., Bai, X., Liang, T. (2013) Serotonin promotes the proliferation of serum-deprived hepatocellular carcinoma cells via upregulation of FOXO3a. Mol. Cancer 12, 14.

Ozunal, Z. G. (2014) Drug development, drug repositioning in oncology. In: 19th World Congress on Advances in Oncology and 17th International Symposium on Molecular Medicine, Athens, Greece, October 9-11, 2014.

Patt, Y., Rojas-Hernandez, C., Fekrazad, H. M., Bansal, P., Lee, F. C. (2017) Phase II trial of sorafenib in combination with capecitabine in patients with hepatocellular carcinoma: INST 08-20. Oncologist 22, 1158-1160.

Peng, L., Gu, L., Li, B., Hertz, L. (2014) Fluoxetine and all other SSRIs are 5-HT2B Agonists - importance for their therapeutic effects. Cur. Neuropharmacol. 12, 365-379.

Raza, A., Sood, G. K. (2014) Hepatocellular carcinoma review: current treatment, and evidence-based medicine. World $J$. Gastroenterol. 20, 4115-4127. 
Reddy, K. K., Lefkove, B., Chen, L. B., Govindarajan, B., Carracedo, A., Velasco, G., Carrillo, C. O., Bhandarkar, S. S., Owens, M. J., Mechta-Grigoriou, F., Arbiser, J. L. (2008) The antidepressant sertraline downregulates Akt and has activity against melanoma cells. Pigment Cell Melanoma Res. 21, 451-456.

Sarrouilhe, D., Clarhaut, J., Defamie, N., Mesnil, M. (2015) Serotonin and cancer: what is the link? Curr. Mol. Med. 15, 62-77.

Schrödter, S., Braun, M., Syring, I., Klümper, N., Deng, M., Schmidt, D., Perner, S., Mülle, R. S. C., Ellinger, J. (2016) Identification of the dopamine transporter SLC6A3 as a biomarker for patients with renal cell carcinoma. Mol. Cancer 15, 10.

Soll, C., Riener, M. O., Oberkofler, C. E., Hellerbrand, C., Wild, P. J., DeOliveira, M. L., Clavien, P. A. (2012) Expression of serotonin receptors in human hepatocellular cancer. Clin. Cancer Res. 18, 5902-5910.

Tesei, A., Cortesi, M., Zamagni, A., Arienti, C., Pignatta, S., Zanoni, M., Paolillo, M., Curti, D., Rui, M., Rossi, D., Collina,
S. (2018) Sigma receptors as endoplasmic reticulum stress "Gatekeepers" and their modulators as emerging new weapons in the fight against cancer. Front. Pharmacol. 9, 711.

Wei, J. C., Meng, F. D., Qu, K., Wang, Z. X., Wu, Q. F., Zhang, L. Q., Pang, Q., Liu, C. (2015) Sorafenib inhibits proliferation and invasion of human hepatocellular carcinoma cells via upregulation of p53 and suppressing FoxM1. Acta Pharmacol. Sin. 36, 241-251.

Xia, D., Zhang, Y. T., Xu, G. P., Yan, W. W., Pan, X. R., Tong, J. H. (2017) Sertraline exerts its antitumor functions through both apoptosis and autophagy pathways in acute myeloid leukemia cells. Leukemia \& Lymphoma 58, 2208-2217.

Xu, J. J., Wang, S. Y., Chen, Y., Chen, G. P., Li, Z. Q., Shao, X. Y., Li, L., Lu, W., Zhou, T. Y. (2014) Dopamine D1 receptor activation induces dehydroepiandrosterone sulfotransferase (SULT2A1) in HepG2 cells. Acta Pharmacol. Sin. 35, 889-898. 